\title{
40Ar behaviour and dynamics of a subduction channel from high-spatial resolution 40Ar/39Ar systematics
}

\author{
VALENTIN LAURENT', STÉPHANE SCAILLET ${ }^{2}$, LAURENT \\ JOLIVET $^{3}$, ROMAIN AUGIER ${ }^{2}$, VINCENT ROCHE ${ }^{3}$ \\ Imperial College London, Prince Consort Road, South \\ Kensington, London SW7 2BP, UK. vlaurent@ic.ac.uk \\ 'Université d'Orléans, ISTO, 45071, Orléans, France \\ ${ }^{3}$ CNRS-UPMC, Sorbonne Université Paris, France
}

In this study, the behaviour of the phengite ${ }^{40} \mathrm{Ar} /{ }^{3} \mathrm{Ar}$ system has been explored from regional to mineral scales through strain gradients previously identified across the Upper Cycladic Blueschist nappe (UCB, Greece). Sub-continuous exposures along these regional gradients provide a rare opportunity to explore the significance of ${ }^{40} \mathrm{Ar} /{ }^{30} \mathrm{Ar}$ ages in terms of exhumation dynamics. Regional-scale mapping of ${ }^{20} \mathrm{Ar} /{ }^{3{ }^{3}} \mathrm{Ar}$ age variations down the crystal size reveals that $H P$ phengites in eclogites and blueschists preserve a complex but consistent record of protracted crystallization ages in the subduction channel between 51 and 37 Ma. Regionally, phengite bulk ${ }^{40} \mathrm{Ar} /{ }^{30} \mathrm{Ar}$ ages (single grains and populations) consistently decrease towards the base of the UCB stack down to $18 \mathrm{Ma}$, in connection with the downward reworking of the HP fabric by the regional GS-grade ductile deformation. Along this trend, only the HP Eocene (51-37 $\mathrm{Ma})$ and GS Miocene (20-18 Ma) age end-members preserve grain-scale homogeneous Ar distributions in the form of plateaus and homogeneous in situ UV-ablation ages. All intermediate ages in between are characterized by variably complex age spectra and discordant in situ ages. Millimetrescale in situ variations far exceed the internal discordance seen in the spectra and encompass almost the full range of apparent ages recorded regionally (up to $26 \mathrm{Myr}$ ). Noteworthy, they mostly occur independent of microstructures and overlapping textural relationships. We interpret the bulk regional age progression and the marked internal discordance as the result of competing mechanisms of ${ }^{\circ} \mathrm{Ar}$ diffusional retention and spatially heterogeneous partial resetting operating at the sub-crystal level. While the downward younging polarity is regionally controlled by the GS thermal overprint locally enhanced by shear localization, grain-scale variations in $\mathrm{Ar}$ retention properties produced a mosaic of sub-domains composed of partially reset to fully preserved relics of early HP clasts coexisting with neocrystallized domains formed during metamorphic reequilibration. This domain-like Ar behaviour occurs below the spatial resolution of the UV-probe $(<50 \mu \mathrm{m})$ and irrespective of phengite compositional variations, indicating that structural and thermal-kinetic crystallographic processes driving ${ }^{\circledR \mathrm{Ar}}$ and stoichiometric recombinations are coupled at small-scale, possibly down the K-interlayer scale. 